\title{
Qual a potência do apoio institucional no campo da saúde pública?
}

Maia MAB, Neves $C A B$. What is the potential of institutional support for the public health field?. Interface (Botucatu). 2014; 18 Supl 1:821-31.

The present paper discusses 'institutional support' as a device for fostering public health policies. In dialogue with the conceptual tools formulated by Deleuze, Guattari, Foucault and Spinoza, we distinguish extensive and intensive support, and argue that the latter is an ethical-political choice to support collective movements that produce instituting processes. To this end, we propose to meddle in the ways of living through the concept-tools of

'interference' and 'life'. We seek to infuse the power of invention of collective devices into institutional support.

Keywords: Institutional support. Public policies. Life. Health management and interference in contemporary life.
O presente artigo discute o "apoio institucional" como um dispositivo para promover políticas públicas de saúde. Dialogando com as ferramentas conceituais formuladas por Deleuze, Guattari, Foucault e Spinoza, distinguimos apoio extensivo e intensivo, postulando o último como uma escolha ético-política de apoio aos movimentos coletivos de produção de processos instituintes. Para isso, propomos interferir nas formas de viver por meio das ferramentas-conceitos de "interferência" e "vida". Procuramos infundir a potência de invenção de dispositivos coletivos no apoio institucional.

Palavras-chave: Apoio institucional. Políticas públicas. Vida. Gestão em saúde e interferências na vida contemporânea.

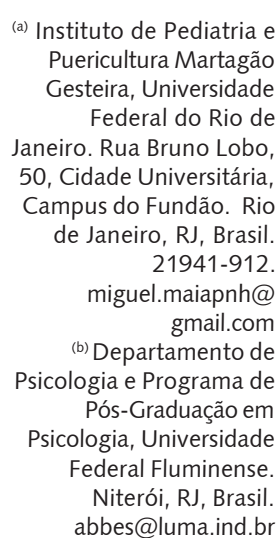

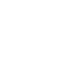


Apoiar é um verbo transitivo, ou seja, exige complemento que Ihe dê um sentido. Sua etimologia deriva do italiano appoggiare, designando: dar apoio a, sustentar, amparar, defender. Appoggiare, por sua vez, deriva do latim appodiãre (podium, subir ao pedestal) ${ }^{1}$. Curiosa esta dupla deriv(ação) do verbo e a incompletude que lhe é constitutiva.

Esta pequena digressão na língua e seus significados e sentidos não busca a expressão de uma erudição academicista e linguageira. Outrossim, nos serve para sinalizar a importância de uma aposta metodológica inclusiva e atenta aos efeitos/produções ético-políticos do apoio nas práticas de gestão, formação e produção de subjetividade. É nesta direção que afirmamos o trabalho de apoio institucional como um dispositivo potente para promover e produzir políticas públicas.

O apoio institucional é comumente associado a ações de financiamento ou ajuda técnica de órgãos oficiais a iniciativas ou projetos específicos. Nesta direção ele envolve uma contratação entre os representantes das partes envolvidas, na qual a escolha de temáticas, metas, ações e investimentos são previamente definidos. Podemos dizer que estas ações em suas distintas e múltiplas contratações marcam um funcionamento, na maior parte das vezes, pautado num fazer "de" (algo, ou alguém) dirigido "para" (outrem, algo, lugar) que intervém "sobre" (um processo, uma situação) visando implantar "algo".

Nestes funcionamentos se desvela uma concepção metodológica na qual sujeito e objeto estão configurados em polos distintos, já bem delineados com relação a suas inserções e, pelo menos em tese, em seus atributos de saber-poder. O modelo de apoio acima descrito se afirma na indicação de caminhos a partir de um 'suposto saber' externo que atua sobre os processos por meio de uma relação descendente.

Assim, podemos dizer que este suposto saber é elevado em um pedestal, em um dos sentidos do vocábulo apoio, configurando-se em um modo de fazer pouco inclusivo da multiplicidade dos movimentos do real e suas interpelações materiais e imateriais no cotidiano dos atores e práticas que o produzem. Pois, estas interpelações fazem emergir um saber constituído nesta experiência vívida que orienta e também interfere nos processos e movimentos outros que o apoio pode disparar.

O que buscamos pensar neste artigo como reflexão teórica é fruto de nossas pesquisas ${ }^{1}$ e, também, de nossas intervenções no campo das práticas de formação, trabalho e produção de saúde, bem como de nossa atuação como psicólogos junto aos profissionais de saúde nos serviços, nas quais temos experimentado a radicalidade do desafio que envolve a construção do trabalho de apoio institucional nos processos de produção da gestão e cuidado nos serviços de saúde. Esta construção implica uma atenção crítica aos possíveis usos político-instrumentais que inscrevem o trabalho do apoio num viés meramente (re)produtor de protocolos, informações, indicadores, arranjos e formas exclusivamente extensivas. Pois, o que pudemos perceber em nossas experiências é que, quando o focamos deste modo, são os saberes e movimentos oriundos desta experiência vívida que corremos o risco de desconsiderar.

No campo da saúde coletiva, podemos mapear a ação de apoio desenvolvida por vários atores ${ }^{2-8}$, que afirmam o trabalho do apoio em sentido diverso à tradição verticalizada (hierarquias de poder-saber) e segmentário-corporativa (grupos-classe profissionais), ainda muito presentes no âmbito da saúde pública. Estes autores, em suas diferenças, propõem outra direção ético-política que se atualiza em arranjos e dispositivos concretos de gestão e cuidado em saúde, afirmados na indissociabilidade entre gestão e atenção e na construção de grupalidades fomentadoras de redes de coletivos que fazem surgir "outros planos de afetos, de encontros, de constituição de redes de conversa, redes afetivas" 7 (p. 4807).

Queremos aqui falar do apoio institucional a partir desta outra direção ético-política, qual seja: apoio como um "modo de fazer" que, em sua relação com um método intensivo, afirma a potência de um espaço limiar como experiência concreta por entre as formalizações extensivas (em seus modos, dispositivos, arranjos, indicadores) como guia para nosso (per)curso. Nesta afirmação o apoio pressupõe como direção menos a pergunta "o que fazer" e mais a pergunta "como fazer" ou "o que se passa por entre os fazeres".

Desta questão, outras se desdobram, tais como: Onde se dá o apoio? O que o apoio dispara? O que entendemos como modo de fazer? Trata-se de uma aposta metodológica que afirma a deriva como "modo-guia" dos encontros e a incompletude do verbo como força constitutiva, na qual e com a qual interferimos e somos interferidos em um transitar por entre as produções dos verbos da vida. É no entre 
deste transitivo, na própria sustentação e defesa de um transitar intensivo, num transita-se, que acreditamos que o sentido da ação de apoiar pode emergir.

Assim, o apoio denominado intensivo, sobre o qual queremos nos debruçar, transita naquele primeiro sentido etimológico: dar apoio a, sustentar, amparar, defender, modulando-se num interferir 'em'.

A ideia de interferência obriga-nos a pensar em inúmeras ocorrências: desde uma ação humana até um vento ou um tropeção. Poderíamos afirmar que um algo qualquer pode interferir em outro, seja para transformar, seja para ratificar um funcionamento. É comum limitar a ideia de interferência a uma espécie de ação de um termo sobre outro, ou, mesmo, como sobreposição de um processo sobre outro. Diferente disto nos interessa pensar as interferências naquilo que produzem de ruídos na comunicação oficial, como efeitos de contágios e ressonâncias plurais, fazendo aparecer outras línguas, sentidos e arranjos coletivos. Pois, no trabalho de apoio que pensamos, não há, de um lado, um apoiador que interfere na realidade de outro que é apoiado, mas um apoiar transitivo que se faz na sustentação de um transitar, que vai traçando um caminho metodológico, na medida mesma em que se experimenta a ação conjunta de traçá-lo no movimento de trânsito.

Em trabalho anterior, $\mathrm{Neves}^{9}$ afirma a interferência como uma relação ou um conjunto de relações de forças que incidem, de maneira casual ou intencional, sobre outra relação ou outro conjunto de relações de forças. Isto quer dizer, nos termos de certas filosofias contemporâneas da diferença, que interferir é estar presente num jogo de forças e, portanto, num complexo jogo de poderes, entendendo que poder implica sempre correlações plurais de forças. Assim, as interferências que nos interessam se dão numa multiplicidade de ações de teoria e prática que transbordam os insuficientes limites do eixo sujeito-objeto. Não se trata de um interferir de um objeto dado sobre outro objeto dado, de uma unidade predeterminada sobre um sujeito preexistente, porém produzir interferências que façam vazar as multiplicidades que constituem a nós e as coisas.

As interferências que nos interessam são aquelas ativadas por potências virtualizantes que, como vimos, reagitam o campo problemático pela exasperação de problemas, sejam grandes ou pequenos. Afirmá-las em seu vetor ativo, como nervura desejante das linhas de fuga, implica acolher a singularidade do acontecimento nas dobras e desdobras que operam em nós, em suas varreduras e contágios. É nesta contaminação que a potência vital se expande, carregando as baterias do desejo e produzindo alegria no corpo como prova da pulsação de uma vitalidade. Vitalidade, esta, que funciona como princípio ético de seleção de escolhas que orientam para onde direcionar as setas de nossas linhas de fuga'.

O desafio, então, é pensar interferências do ponto de vista da produção social da existência, como movimentos que se constroem na experimentação, e não como regra exterior ou ativismo programático, previamente traçado, entre um sujeito que interfere e o estado de coisas no qual se quer interferir.

O princípio que norteia o trabalho de apoio requer produção de protagonismo e autonomia dos sujeitos e, desse modo, a participação coletiva no processo de gestão e formulação das políticas públicas assume um lugar fundamental. Pautar como princípio o protagonismo de usuários, profissionais e gestores significa ir além da participação nos canais instituídos e já formalizados.

A noção de apoio não se traduz como integração, como cumprimento de rituais administrativos e burocráticos. Os princípios de coconstrução no processo de apoio pretendem ressaltar que participar implica intervir, bifurcar, interferir na produção cotidiana das políticas de saúde. Quando se entende que a política é constituída de procedimentos ativos de invenção e recriação permanente das normas, falamos de um modo de operar as políticas públicas que se quer aberto às múltiplas interferências e à heterogênese de problemas que (re)agitam seu campo problemático.

Mas aonde incidem estas interferências? Sobre o que se interfere e como se interfere?

\section{Apoio em sua face intensiva: de que interferência falamos?}

Efetuar-se ou ser efetuado significa: prolongar-se sobre uma série de pontos ordinários; ser selecionado segundo uma regra de convergência; encarnar-se em um corpo, tornar-se estado de um corpo; reformar-se localmente para novas efetuações e novos prolongamentos limitados. Nenhuma 
destas características pertence às singularidades como tais, mas somente ao mundo individuado e aos indivíduos mundanos que o envolve; eis por que a efetuação é sempre, ao mesmo tempo, coletiva e individual, interior e exterior etc. ${ }^{10}$.

Macropolítica (molar/extensivo) e micropolítica (molecular/intensivo) são dois modos de recortar a realidade, são planos indissociáveis que, apesar de terem seus modos próprios de funcionamento, atravessam-se o tempo todo. Eles correspondem ao que Rolnik ${ }^{11}$ (p. 59) chama de "duas formas de individuação, duas espécies de multiplicidades, [...] duas políticas". O plano molar seria o plano da segmentariedade dura, do visível, dos processos constituídos, onde encontramos a predominância das linhas ${ }^{(c)}$ duras (família, profissão, trabalho etc.). Estas estão subordinadas a um ponto de referência que lhes dá sentido e implicam dispositivos de poder diversos que sobrecodificam os agenciamentos em grandes conjuntos, identidades, individualidades, sujeitos e objetos. O plano molecular, por sua vez, refere-se ao plano do desejo, do invisível, onde não se tem unidades, mas intensidades. Nele, temos a predominância das linhas flexíveis (fluxos, devir etc.), que buscam se desviar da sobrecodificação totalizadora das linhas segmentares e as linhas de fuga (abstratas) que, compondo um plano submolecular, conectam-nos com o desconhecido, operando aberturas para um campo de multiplicidades.

Os aspectos extensivos (molares) e intensivos (moleculares) da interferência coexistem num mesmo movimento; sabemos que os "movimentos ondulatórios" que nos produzem e produzimos não se dão "num lago calmo", mas em meio às "ondas do mar" que nos jogam em funcionamentos e que também deles nos retiram, lançando-nos em meio a outros movimentos que, perturbando nossos "portos seguros", forçam-nos a inventar inseguranças nômades, temporárias e fugazes, para o viver e o existir.

É nos encontros que experimentamos os movimentos que nos forçam a problematizar, mais do que a responder; alterando a nossa subjetividade e abrindo-a para o intensivo, já ali aonde os conceitos viram fluxo de intensidade e nos conectam no circuito ziguezagueante da coexistência macro/ micropolítica.

Uma interferência goza de dimensão extensiva quando atualiza um acontecimento intensivo em formas (usuário, profissional, gestor), em segmentos (divisão, seção, setores), ou séries causais (paciente da cardiologia, funcionário da cooperativa, gestor do Ministério). Estas atualizações são reportáveis a uma "intenção de" que implica a produção de territórios que sirvam seja para neutralizar e/ou estabilizar as desterritorializações intensivas, seja para servir de suporte para disciplinadas e convergentes pausas programáticas, ou, até mesmo, para "dar um tempo" nas desestabilizações como pausa tensa. Dentre as diversas possibilidades de configuração destes territórios, destacamos as formas que nos parecem as mais recorrentes em nossas interferências extensivas.

Quando as desterritorializações intensivas, que não nos permitem grudar nos enquadres de segmentos e formas, são neutralizadas ou estabilizadas num território, tecem-se práticas que podem estancar-se em oposições abstratas e burocratizadas tanto no nível de organizações (políticas, sindicais, religiosas, de saúde etc.) que se pautam num "dever de militância", quanto no nível comunicativo de enunciados genéricos (palavras de ordem presentes em modos de comunicação segmentarizados). É quando se monta uma máquina burocrática na qual, de feitas por humanos, as normas passam a ser feitas para os humanos. Neste funcionamento, os processos inventivos podem se engessar num prescritivo que vira lei e interdição para qualquer mudança. As normas perdem força instituinte quando o seu único sentido é a interdição e a instauração de dualismos morais e opositivos nos modos de fazer e viver.

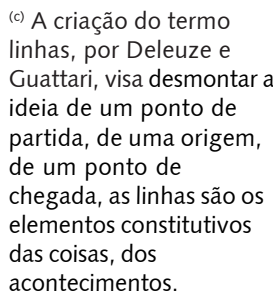


Uma interferência goza de dimensão intensiva quando é capaz de acolher um acontecimento imanente, no qual se constituiu em sua mobilidade intensiva, fora das coordenadas espaço-temporais, não o confundindo nem com o vivido, nem com o estado de coisas e enunciados no qual ele se atualizou e foi enunciado. Quando é capaz de fazer o acontecimento ressoar sua potência disruptora, cintilando um conjunto indeterminado de perspectivas que não o esgotam, mas se dispersam e nos lançam numa miríade de problemas, de sentidos, de transrelações desestabilizadoras que agitam partes do estado de coisas, arrastando-o para novos acontecimentos e composições.

Uma interferência intensiva funciona como obra aberta e por relações de vizinhança entre devires. Constrói consistências provisórias sensíveis ao campo problemático que as dobra, desdobra, redobra em ressonância com os gritos de dor e de alegria que pulsam na intensidade vital.

São interferências deste último tipo que, acreditamos, ganham relevo e insistem em nosso contemporâneo. Ao dizermos isso, porém, não queremos cair na armadilha de opor um tipo de interferência micro a outro tipo que seria o das macrointerferências. A rigor, há sempre pressuposição recíproca entre interferências extensivas e intensivas, sejam elas pequenas ou grandes, capazes de maior ou menor alcance. O que importa, em cada caso, é distinguir qual é o regime (se intensivo ou extensivo) que envolve nossa participação nela, e que cintila nas alianças que se tecem através dela9; i ́ distinguir o que aumenta a potência de nosso transitar pelos verbos da vida (viver, sentir, trabalhar...) do que a enfraquece em um vivível pleno de prescrições que já não faz mais sentido.

Tais dimensões não existem separadamente, mas, sim, coexistem em um mesmo movimento, são forças em relação que criam ressonâncias que tanto podem inibir ou proliferar sentidos e modos de vida. O que aqui procuramos esboçar, mantendo como proposta teórico-prática a ser desdobrada, é que o real comporta a possibilidade concreta de acolhermos e construirmos um regime de interferências, um interferir que, dando "sinal de vida", funcione para que a disparidade dos problemas se evidencie. Esse regime contrasta, obviamente, com aquele de proposições fechadas voltado para um programa de interferências disciplinadas e de cunho meramente extensivista.

\section{O apoio institucional: de onde se parte?}

Quando o apoio que aqui defendemos encontra o cenário aonde deverá atuar, parte do princípio de que este cenário é, na verdade, uma arena onde se embatem forças que, em seus agenciamentos, são potencialmente produtoras de sentidos, modos, instituições, capazes de convergir, de divergir ou, simplesmente, conviver lado a lado, como mundos incompossíveis que habitam este plano em que consistem as formas que emergem à superfície. Assim, com o que primeiro nos deparamos é com um espaço extensivo constituído, num tempo marcado, com definições já dadas de posições, de relações e de afetações entre os atores que possuem uma história, constroem sentidos, formam um contexto político que é preciso, então, conhecer e mapear.

Neste mapeamento, para o qual é imprescindível contar com os profissionais da organização envolvidos diretamente na ação demandada e na gestão cotidiana das mesmas, nos deparamos com uma miríade de processos e funcionamentos que sinalizam certa correlação de forças perpassadas por uma multiplicidade de linhas. A ação de linhas duras produtoras de binarização, oposição e homogeneização que expressam modos e arranjos instituídos e cristalizados - tomados como dados desde sempre e que, muitas vezes, sequer são questionados - afins aos tempos, dispositivos e arranjos institucionais das políticas de Estado e de governo, mas, ao mesmo tempo, também a ação de linhas de fuga produtoras de singularizacão, que fazem estranhar e diferir as histórias assentadas, seus enunciados e tempos político-institucionais. Como estar atento ao que, no trabalho, é índice de movimento-criação?

Assim, não é neste instituído cristalizado que incidirá, primordialmente, a ação do apoio. Ele é apenas o contexto que nos orientará e nos guiará, como que num campo minado, no qual se pisa com prudência e muita atenção. Porém, é deste campo minado que se parte, mapeando as adversidades e tomando-as como questões que precisam ser problematizadas, como um movimento já dado que precisa tomar algum outro rumo, que não o que está em curso, pois foi este quem determinou a demanda do apoio. Demanda que, por princípio, entendemos como encomendada, mas ainda não formulada, não construída, já que somente no encontro com aquela instituição e com os atores 
envolvidos é que emergirá aquilo que é realmente o problema. Portanto, a demanda e o lugar do apoio 'habitam' um não-lugar, um nó entre o atravessamento do jogo de forças posto em ação e a configuração das formas que aparecem. Inscrevem-se na produção de uma experiência limiar entre texto e contexto, na interface entre aparência e transparência, num rosto em mutação constante no qual tudo aparece como máscara, como disfarce.

Um não-lugar em que nos dispomos numa disposição, pois, ao nele adentrarmos, passamos, imediatamente, a fazer parte do contexto, interferindo no jogo de forças e na configuração de formas e arranjos instrumentais. Nesta disposição, há que se estar atento, já que implicados sempre estamos naquilo que nos dispomos, naquilo que somos postos e naquele algo que 'se põe' como efeito e produção coletiva. Neste 'se posto' é preciso, então, uma disposição: como desejo de interferir, já que, para isto, fomos demandados; mas, também, disposição no sentido de não nos situarmos, de estarmos sempre nos deslocando, desfocando, a fim de evitarmos a forte tendência de sermos centro.

Paradoxalmente, nosso trabalho nas práticas de apoio se tece/é tecido em meio à convocação, em nós, de práticas intensivas de vitalização e produção de processos coletivos que implicam, ao mesmo tempo, uma outra duração intensiva (do acontecimento) e ações extensivas afins aos tempos, dispositivos e arranjos institucionais das políticas de Estado e de governo.

Pensamos, aqui, como é rotineiro o uso das prescrições e protocolos, ou mesmo de programas ou políticas, já dados de antemão e instituídos, sobre os quais não incidem mais a visão crítica, ainda que estejam descolados da realidade do presente, funcionando como homogeneização das políticas cognitivas e das condutas que aparecem como devendo ser tomadas simplesmente porque "é assim que deve ser feito" ou "as regras são essas". Cada qual se enclausura em modelos repetitivos, tão blindados pelo lugar que ocupam na instituição, fazendo parecer que o cuidado com a saúde está limitado a um espaço definido rigidamente, "trincheira tão funda que, impedindo de fato de ser visto, vai mais longe e acaba por não permitir ver mesmo nada". ${ }^{12}$ (p. 193)

Tipo de implicação na área de saúde que alimenta as dificuldades de construção de um trabalho coletivo e solidário, produzindo profissionais individuais e individualizantes, salvando-se como e quando podem do trabalho (aparentemente impossível de ser bem-feito), do salário insuficiente, do contato com a dor própria em contato permanente com a dor alheia ${ }^{13}$.

Trata-se, primordialmente, de interferir na produção de políticas de subjetivação que, fazendo-se crer como hegemônicas, acabam decretando ou revigorando a "claustrofobia política dominante" 14 ( $p$. 41) e, comprometendo de antemão nossa mobilidade, enclausuram os combates afirmativos e criativos nos modos de habitar os verbos da vida em condutas de resignação, de tédio e de culpa, o que Nietzsche denominava má consciência.

Por isto, pensamos nas interferências que, como propõe Foucault ${ }^{15,16}$, se aliam à expansão dos índices de liberdade, aos sinalizadores de vetores da diferença que podem indicar a produção de uma outra estética da existência: de uma vida como obra de arte.

\section{A vida como potência de combate: o que pode o encontro dos corpos}

Quando nos propomos a trazer, para nossa conversa, um conceito de vida, nos vemos imediatamente enredados com os perigos de sua generalização e consequente redução/mortificação. Sejam pelos limites de finitude, constitutivos da linguagem na expressão de processos infinitos e singulares, que criam na própria vida empírica os entretempos que elevam esta vida empírica a dimensões nem mesmo sonhadas, seja pelo entendimento de que falar de vida implica sempre falar de "uma vida", impessoal e, ao mesmo tempo, singular.

Deleuze, ${ }^{17}$ em seu último texto, "Imanência uma vida", marca a importância do uso do artigo indefinido 'uma vida,' afirmando a vida como povoamento de variações intensivas, de dobras, que se atualizam em nós e nas coisas como 'entre-tempos e entre-momentos' que não marcam um tempo entre dois instantes, mas coexistem com o instante em seu porvir. Desse modo, 'uma vida' não encontra referência numa pessoa ou num fato que a transcende, mas em si mesma como potência singular em imanência com aquilo que age e faz agir os corpos em suas múltiplas combinações e invenções. 
Temos aí a afirmação de um conceito de vida que não se compõe apenas de biologia, fisiologia, natureza e subjetividade como campos que se relacionam guardando suas delimitações, mas como experiência germinativa singular sem identidade subjetiva e sem consciência. Plano virtual,

pré-individual e, portanto, impessoal -e, ao mesmo tempo, singular - opõe-se aqui ao transcendente, em suas laminações identitárias e representacionais coladas aos corpos, estados de coisas e aos enunciados. Um plano de proliferação, de relações de forças que, em suas criações e recriações, traçam, na molecularização de formas, funções e organizações, outras composições que podem reforçar estas formas e organizações ou recriá-las ${ }^{9}$.

Uma vida é aqui afirmada em seu processo de conectividade intempestiva, um fora absoluto, em constante estado de criação e recriação. Pois, quando ancoramos a vida num transcendente e em abstrações, interrompemos a errância, a experimentação, introduzindo uma interpretação e uma fixação, mesmo que temporárias.

A vida, então, pensada como potência de combate, compõe-se em meio a processos plurais de racionalização, em meio a negociações de políticas cognitivas. É nesta perspectiva que Foucault ${ }^{16}$ vai afirmar a liberdade como um exercício, como práticas de liberdade que acontecem naquilo que fazemos para nos transformar. Este exercício opera uma crítica no limite de nós-mesmos e se afirma como processo permanente de problematização e de ultrapassagem dos limites históricos que nos constituem em seu estado de coisas e de enunciados.

Nesta direção, ao desnaturalizar a ideia de vida como pressuposto de uma essência humana; como latência à espera de resgate por uma ação sobre o que a constrange, seja esta ação individual ou coletiva, ele afirma a vida em sua plasticidade imanente, e nos incita à ativação de um devir ativo que se compõe como movimento de exploração de vizinhanças, segundo conexões não previamente estabelecidas.

É com este conceito de vida que, em nossa compreensão, se afirma a produção de uma política de apoio ao SUS e o campo problemático no qual e em meio ao qual se produzem as ações de apoio em seus princípios, diretrizes e dispositivos de intervenção.

O apoio institucional, seguindo os princípios, diretrizes e dispositivos que aqui pensamos, se norteia pela ativação deste devir ativo, buscando, ali aonde nada mais parece ser possível, na potência daqueles que por ali transitam, um outro modo de fazer para aquilo que é sentido como intolerável. Neste entendimento, não é através de modos de fazer meramente extensivos, muitas vezes 'vendidos' como um suposto saber externo de quem sabe todas as respostas, que ativamos, na experiência do apoio, modos de passagem para que se possa 'fazer gritar os problemas', mas através de uma atitude de prudência e atenção ao que, no processo de ação de apoio, é signo de ultrapassagem e criação.

Prudência por saber que não sabe do que ali se passa, quando inicia o apoio; por acreditar firmemente que é, através das experiências que ali se dão, que qualquer movimento será possível; por ter por princípio que o saber da experiência é o motor de qualquer interferência intensiva; por saber que o sentido é construído coletivamente, e, sobretudo, por se nortear por uma metodologia que se constrói em meio ao intempestivo. Construção, esta, não sem riscos, mas completamente implicada num apoia-se que nos produz, ao mesmo tempo, como produção e produto de um apoio que, na heterogênese, traça seu caminho enquanto transita. E neste transitar, esperando, como produto, não o atingir de uma meta previamente traçada, mas o pôr em movimento protagonistas que, armados de método, saibam autonomamente construir caminhos que, ainda que com desvios, se tracem na direção do que os afeta como aumento da potência de habitar os verbos da vida.

É no encontro, neste meio de proliferação, que os corpos expressam sua potência de afetar e ser afetado. É nele que o desejo flui e cria mundos, agenciando modos de expressão e a conectividade da vida em suas múltiplas experimentações ${ }^{18}$.

Espinoza, em sua leitura dos estoicos, nos mostra que a lei da vida é a lei dos encontros. Todo corpo vivo faz necessariamente, ao longo da sua existência, uma série de encontros com outros corpos. É nestes encontros que o ser vivo efetua a sua potência de afetar e ser afetado, ou, poderíamos dizer, de interferir e sofrer interferências. O afeto só existe em composição, em agenciamento, e deste modo só pode ser pensado em sua função. Nesta direção ele não é um sentimento, uma paixão ou emoção, mas aquilo que faz a composição dos corpos, denominada por Deleuze e Guattari ${ }^{19}$ como agenciamentos. 
O agenciamento é a liga do desejo na produção de mundos. Uma multiplicidade substantiva que comporta termos heterogêneos e estabelece entre os termos relações diferenciais imanentes, de modo que um termo da relação não se torna outro, se o outro já não se tornou outra coisa. Por isso, sua única unidade é a de cofuncionamento, ligando estado de coisas, estado de corpos e enunciados em relações de vizinhança com limites móveis e sempre deslocados.

Num agenciamento não se encontra sujeito e objeto constituído, mas agenciamentos coletivos de enunciação e agenciamentos maquínicos trabalhando, ao mesmo tempo, sobre fluxos semióticos, materiais e sociais, que arrastam as pessoas e as coisas em suas engrenagens ${ }^{18}$. Os agenciamentos geram acontecimento e, em seu poder de "comunicação de heterogêneos", efetuam mundos possíveis, para além ou aquém daquele que, naturalizado, se apresenta como um modo de fazer hegemônico e cristalizado.

Ali mesmo onde algo está constituído como único possível, uma multiplicidade de possíveis pululam, como heterogêneos modos de fazer, sempre também possíveis, mas diríamos que cristalizam a produção de desejo em uma política cognitiva por demais conservadora do status quo.

Interferir intensivamente neste estado de coisas é, então, treinar os ouvidos para este ronco surdo que se maquina naquilo que se repete como sempre repetição. É ouvir este silêncio que grita na concha fechada do instituído e reverbera numa fissura capaz de abri-la para a expressão instituinte. Interferir é, então, ferir dentro daquilo que está interdito ou homogeneizado para que, ao se dizer, passagens se criem por entre heterogeneidades, fazendo ganhar a cena vozes minoritárias, o entre os ditos. Diz de uma experimentação intensiva como efeito da maquinação de corpos em suas relações, em uma deriva de efetuação e de afetação, produtora de outros possíveis e criação de mundos arrastados pelas forças instituintes.

O corpo é uma multiplicidade de potências, não existe uma unidade corporal. Todos os corpos são sempre uma multiplicidade de corpos se agenciando com uma multiplicidade de outros. São essas potências que estão - o tempo inteiro - se confrontando e conduzindo a nossa vida, são estas potências que criam mundos.

Neves ${ }^{9}$, ao discutir o conceito de vida, em seu processo imanente de variação contínua, mostra que as regularidades não são "primeiras", mas, sim, o 'corpo errante' como potência em constante engendramento e produção. Ao dizer, paradoxalmente, que o corpo como potência é "primeiro", já que neste plano se conjuram as origens e hierarquias, queremos afirmar que este corpo de "pura" intensidade é produzido e se produz como diferenciação constante nas relações de forças. Ele não está em oposição a suas configurações em formas, funções ou organizações de poder. Diferente disto, estas configurações são uma de suas nervuras, e não redundam, necessariamente, na dissolução da singularidade deste corpo. Nelas, a expressão de suas potências é limitada pelas formas para tornar a vida vivível. Mas o que é vivível em um momento, nesta limitação das potências pelas formas, não é de modo algum uma regra estabelecida para sempre, não é de modo algum o único vivível possível para todos os momentos.

A potência, para ser vivível, se limita na forma, mas não a potência da vida. Na própria forma limitada e, portanto, vivível, há graus heterogêneos de potência que coexistem com a limitação, podendo abri-la para outros vivíveis. As formas são estados momentâneos de cristalização das forças, ou, como vínhamos dizendo, o extensivo, a forma cristalizada, comporta, em si mesmo, o intensivo, as forças de abertura. Buscar nestas formas a sua fissura é poder ouvir o ronco do que aquilo que um dia foi um vivível não está mais tolerável, é dar vazão às forças em movimento para que efetuem um novo possível vivível.

\section{O apoio institucional: um modo de fazer política pública}

O apoio institucional, nestas premissas, é transitivo como o verbo, seu sentido só emerge na ação de o pôr em movimento. Diferente do apoio extensivo, o apoio intensivo tem como principal produto a formação de apoiadores, instrumentar aqueles, que, supostamente, 'não sabem', a fazer-saber e a saber-fazer, com a certeza de que o como fazer é uma produção sempre coletiva. Esta a principal meta que não vem antes da intervenção/interferência, mas se constitui na afetação que o próprio apoio tem 
como função fazer emergir, acordando os sentidos de uma anestesia de saberes hegemônicos e descendentes. Saberes, estes, que dificultam a emergência de outros possíveis aos modos instituídos de habitar os modos da vida.

O apoio se dará, como dissemos acima, neste não-lugar-tempo, sempre entre, sempre limiar, sempre deriva, sem centro, um U-topos intempestivo aberto ao acontecimento. É no esforço de constituir este nômade $U$-topos que, ao mesmo tempo, vamos nos dando conta do que passa, do que não passa, cartografando aquilo que entendemos como demanda, que emerge deste tenso contexto heterogêneo, a fim de, então, podermos fazer uma oferta de interferência.

Ferimos, então, dentro o instituído, levando-o a se problematizar, fazendo passar o que não passa, acolhendo o heterogêneo e construindo espaço de expressão para que, enfim, o segredo e o secreto se desvelem e não tão só se revelem na transparência das aparências. Incluir os conflitos, fazê-los se expressar abertamente, faz surgir novas configurações, novos arranjos de forças que, então, passamos a utilizar como analisadores.

Neste ir e vir de analisadores sociais, a capacidade de análise se expande, permitindo que as forças de emergência adentrem o micro contexto, porém, agora, através de uma esfera macro. Começamos a incluir o fora das instituições de saúde, os movimentos sociais e sensíveis, capazes de nos apontar novos antagonistas, agonismos e novos parceiros.

O apoio é, então, um dispositivo de abertura das comunicações, de romper verticalidades (hierarquia) e horizontalidades (corporação), arrastando, numa deriva, as regras e as interdições. Todos falam com todos, todas as vozes têm voz e importância neste círculo que faz a roda girar, todos são cogestores das adversidades e das proposições e, portanto, todos são corresponsáveis na efetuação de possíveis.

Assim, o agenciamento coletivo de enunciação (a comunicação transversalizada) e o agenciamento maquínico dos corpos (protagonismo, cogestão e corresponsabilização) são capazes de, num átimo, deslanchar movimentos criativos onde tudo era só repetição, onde tudo era parada resignada e ressentida. Aparecem as forças afirmativas e um engajamento na ação. Surgem, não sem dor, rachaduras na máquina burocrática, o tédio é ferido de morte e não há outro jeito a não ser, como sempre foi, se implicar com movimentos outros, pois, lembramos, implicados sempre já estamos.

Porém, a implicação agora é outra, ela tem a força da alegria de um possível de renovação. “Um pouco de possível, senão eu sufoco!" 20 (p. 131) parece ser, em nossa experiência de apoiadores, a primeira e única demanda, num meio de "ai, ai, ais e ui, ui, uis" em que nada consegue se mover. Não nos enganemos, a máquina burocrática é pesada, mortífera, castradora e despotencializadora.

Aqui podemos afirmar, pensamos que, agora, de forma clara, que o apoio interfere na inércia, tendo como principal meta o movimento. Não um movimento imposto de fora, não um empurrão que leva, em seguida, novamente ao estático ou à queda brusca e violenta, mas um movimento construído de dentro, vindo de dentro da própria inércia, uma co-moção, capaz de fazer visibilizar, inclusive, os êxitos já alcançados e que devem ser aprimorados, disseminados, estendidos, compartilhados, convividos. O que antes parecia impossível pela mortalha chorosa de um passado glorioso que nunca existiu.

Assim, neste movimento nada fácil, nada dado, nada seguro, no qual tudo é esforço e risco, quais são, enfim, os efeitos possíveis deste tipo de apoio que defendemos:

1) dispara movimento de mudança nos processos de produção de saúde e de produção de subjetividade, abrindo possíveis nas formas cristalizadas de analisar os problemas e buscar soluções imediatas sem respaldo no coletivo de trabalhadores;

2) dispara processos de grupalização e de montagem de redes de coletivos, já que as construções são realizadas pelos coletivos de trabalho, por aqueles envolvidos e diretamente interessados nas melhorias de suas condições de atuação, aumentando o grau de protagonismo e autonomia, porém com corresponsabilidade, minorando práticas individualistas e individualizantes. Na medida em que a análise de cenário ganha potência, as negociações entre equipes de trabalho e com outras unidades da rede passam a entrar na ordem do dia, criando verdadeiras redes de colaboração no e entre serviços;

3) dispara processos de alterização, já que envolve os trabalhadores na negociação constante de suas práticas, tomando em consideração os fluxos de trabalho, minorando a visão fragmentada e individualizada de tarefas a serem executadas, e aumentando o grau de pertinência e de compreensão dos processos de trabalho em toda a sua linha de cuidado, já que falamos, aqui, a das práticas de saúde. 
Estejamos atentos, dispara processos e, como tais, nunca findos, nunca dados, nunca êxito final sobre as adversidades. É preciso que este novo vivível continue se processando, pois a tendência de se instituir como modelo, como regra dada, como norma e meta a ser seguida para sempre é um espectro que sempre nos acompanhará.

Assim, como dissemos acima, a importância para este tipo de apoio ser, talvez antes de tudo, um processo de formação. O apoio intensivo, como o entendemos, não terá tido êxito se, ao sair da interferência/intervenção, não tiver formado apoiadores, não tiver munido os trabalhadores - e todos o somos - de métodos, não para implantar os dispositivos de uma dada política, mas para, a partir de sua experiência vivida no suor e na carne, poder inventar dispositivos de novos movimentos futuros.

O apoiador, nessa direção ético-estético-política, chega como quem não sabe, faz o esforço de continuar não sabendo durante todo o processo e sai como quem não sabe se o processo continuará. Chega com a insuficiência do que já sabe e vazio no sentido das prescrições, mas não sai 'vazio'. Sai enriquecido pela experiência, certo de que a noção de êxito e de fracasso depende menos de uma meta alcançada que de uma experiência compartilhada.

E sai na espera de que aqueles que estiveram envolvidos estejam agora como ele, sabendo fazer, sabendo fazer-saber e, acima de tudo, sabendo não saber. Sabendo que política pública é aquela que tecemos no encontro dos corpos, quando, numa construção comum, combatemos o bom combate, na busca de efetivar um comum compartilhado que mereça ser denominado, com a força do nome, política pública.

\section{Colaboradores}

Os autores trabalharam juntos em todas as etapas de produção do manuscrito.

\section{Referências}

1. Cunha AG. Dicionário etimológico da Língua Portuguesa. 3a ed. Rio de Janeiro: Lexikon Editora Digital; 2007.

2. Merhy EE, Onocko R, organizadores. Agir em saúde: um desafio para o público. São Paulo: Hucitec; 1997.

3. Campos GWS. Saúde Paidéia. São Paulo: Hucitec; 2003.

4. Campos GWS, Guerrero AP, editores. Manual de práticas de atenção básica: saúde ampliada e compartilhada. 2a ed. São Paulo: Aderaldo \& Rothschild; 2010.

5. Pasche DF, Passos E. Inclusão como método de apoio para a produção de mudanças na saúde - aposta da Política de Humanização da Saúde. Saude Debate. 2010; 34(86):423-32.

6. Merhy EE. Micropolítica do encontro intercessor apoiador-equipe, substrato para um agir intensivista. Saude Debate. 2010; 34(86):433-5.

7. Barros MEB, Guedes CR, Roza MMR. O apoio institucional como método de análiseintervenção no âmbito das políticas públicas de saúde: a experiência em um hospital geral. Cienc Saude Colet. 2011; 16(12):4803-14.

8. Oliveira GN. Devir apoiador: uma cartografia da função apoio [tese]. Campinas (SP): Faculdade de Ciências Médicas, Universidade Estadual de Campinas; 2011. 
9. Neves CEAB. Modos de interferir no contemporâneo: um olhar micropolítico. Arq Bras Psicol. 2004; 56(1):2-19.

10. Deleuze G. Lógica do sentido. 4a ed. São Paulo: Perspectiva; 1974.

11. Rolnik S. Cartografia sentimental: transformações contemporâneas do desejo. São Paulo: Estação Liberdade; 1989.

12. Da Silva CO. Curar adoecendo: um estudo do processo de trabalho hospitalar em busca da saúde, da inventividade e da vida [dissertação]. Rio de Janeiro (RJ): Escola Nacional de Saúde Pública, Fundação Oswaldo Cruz; 1994.

13. Maia MAB. O corpo invisível do trabalho: cartografia dos processos de trabalho em saúde [dissertação]. Niterói (RJ): Faculdade de Psicologia, Universidade Federal Fluminense; 2006.

14. Pelbart PP. A vertigem por um fio: políticas da subjetividade contemporânea. São Paulo: Iluminuras; 2000.

15. Foucault M. Dits et écrits. 1954-1988, IV 1980-1988. Paris: Gallimard; 1994.

16. Foucault M. Em defesa da sociedade. São Paulo: Martins Fontes; 1999.

17. Deleuze G. A imanência, uma vida... In: Vasconcellos J, Fragoso EAR, organizadores. Gilles Deleuze - imagens de um filósofo da imanência. Londrina: Ed. UEL; 1997. p. 15-9.

18. Neves CEAB. Gilles Deleuze e política: interferências nos modos de se estar nos verbos da vida. In: Tedesco S, Nascimento ML, editores. Ética e subjetividade: novos impasses no contemporâneo. Porto Alegre: Sulinas; 2009. p. 192-213.

19. Deleuze G, Guattari F. Kafka: por uma literatura menor. Rio de Janeiro: Imago; 1977.

20. Deleuze G. Conversações. Rio de Janeiro: Editora 34; 1992.

Maia MAB, Neves CAB. Cual es la potencia del apoyo institucional en el campo de la salud pública?. Interface (Botucatu). 2014; 18 Supl 1:821-31.

El presente artículo discute el "apoyo institucional" como un dispositivo para promover políticas públicas de salud. Dialogando con las herramientas conceptuales formuladas por Deleuze, Guattari, Foucault y Spinoza, distinguimos apoyo extensivo e intensivo, postulando el último como una elección ético-política de apoyo a los movimientos colectivos de producción de procesos instituentes. Para eso, proponemos interferir en las formas del vivir por medio de las herramientas-conceptos de "interferencia" y "vida". Buscamos infundir la potencia de invención de los dispositivos colectivos en el apoyo institucional.

Palabras clave: Apoyo institucional. Políticas públicas. Vida. Gestión en salud e interferencias en la vida contemporanea.

Recebido em 23/04/13. Aprovado em 03/11/13 
